\title{
Fundamentos do Compliance para Regulação das Ações Empresariais
}

\author{
Fundamentals of Compliance for Regulating Corporate Actions
}

\author{
Marcos Antônio Madeira de Mattos Martins*a; Karla Cristina da Costa e Silva de Mattos Martins ; Angelo Palmisano ; \\ Alessandro Marco Rosini ${ }^{\mathrm{d}}$ \\ ${ }^{a}$ Faculdade de Direito de Franca, Pós-Graduação Lato Sensu em Direito. SP, Brasil. \\ ${ }^{\mathrm{b}}$ Centro Universitário das Faculdades Metropolitanas Unidas, Pós-Graduação Lato Sensu em Direito. SP, Brasil. \\ ${ }^{\mathrm{c} C e n t r o ~ U n i v e r s i t a ́ r i o ~ d e ~ V a ́ r z e a ~ G r a n d e, ~ P o ́ s-G r a d u a c ̧ a ̃ o ~ L a t o ~ S e n s u ~ e m ~ D i r e i t o, ~ M T, ~ B r a s i l . ~}$ \\ dUniversidade Anhanguera, Pós-Graduação Lato Sensu em Direito, SP. Brasil. \\ *E-mail: marcosmartinsadv@gmail.com
}

\begin{abstract}
Resumo
Nas organizações subsiste uma cultura generalizada de que os sócios e os investidores, detentores do Poder Administrativo das organizações, exigem que as empresas obtenham lucro a todo custo, ainda que as decisões infrinjam normas ou violem a prática do bom comportamento humano. A presente pesquisa utilizou método teórico investigativo para interpretar as ações e as decisões do homem, a partir de ritos e de padrões criados por rotinas sociais e organizacionais. O resultado demonstra a necessidade de imposição de um Código de Ética e da execução de Compliance para o controle da gestão de decisões e efetividade da responsabilidade social, estacando condutas corruptivas e evitando resultados maléficos a curto ou longo prazo para a empresa e a sociedade.
\end{abstract}

Palavras-chaves: Compliance. Ética. Regulação. Gestão. Organização.

\begin{abstract}
At the organizations there is a widespread culture that partners and investors, who have the administrative power of organizations, require companies to make a profit whatsoever, even if the decisions violate standards or violate good human behavior. The present research used investigative theoretical method to interpret the people's actions and decisions from rites and standards created by social and organizational routines. The result demonstrates the need to impose a Code of Ethics and Compliance enforcement to control the decisions management and the social responsibility effectiveness, stopping the corruptive conduct and avoiding short- or long-term malicious results for the company and society.
\end{abstract}

Keywords: Compliance. Ethics. Regulation. Management. Organization

\section{Introdução}

O ser humano precisa do trabalho para subsistência própria e de sua família. O trabalho representa ao homem o exercício de sua condição humana como agente produtor de bens, modificando o estado natural das coisas. Por ser agente modificador do meio ambiente, o homem produz ações com a finalidade de alterar o estado em que se encontra o meio social, utilizando-se do seu intelecto como válvula propulsora das inovações.

A história traz elementos enriquecedores das circunstâncias pelas quais as necessidades provocaram ao homem o estudo e o experimento de novas técnicas para descoberta de novos artefatos, que propiciem mais segurança e comodidade às famílias e à sociedade.

$\mathrm{O}$ interregno que medeia a descoberta do fogo até o uso da nanotecnologia demonstra uma soma exorbitante de séculos, que o homem necessitou para explorar e executar experimentos, criando tecnologias para atender aos interesses sociais. Se a roda modificou o meio de transporte na antiguidade, no século XIV e XV, por exemplo, as inovações estavam focadas nas navegações marítimas, porque o homem buscava o desbravamento de novas terras, que estavam além dos oceanos, em terras mais distantes.

No final do século XIX e início do século XX, a descoberta do vapor e o incremento de processos produtivos, por meio de máquinas, modificou a exploração econômica da sociedade, de tal modo que os trabalhadores, que estavam no campo, passaram a vender sua força de trabalho para os grandes empreendedores fabris.

Nesse pequeno trecho histórico se pode verificar que o homem buscou e busca, através da técnica, modificar e atualizar os objetos, que estão disponibilizados na natureza ou produzidos pelas organizações, a fim de atender as necessidades dos mercados em cada momento histórico.

As técnicas foram sendo modificadas durante a história, mas a ganância do homem demonstra o nódulo que reside no organismo social, resultando em danos sociais a toda comunidade.

No Brasil, o atual cenário em que se desembocam algumas empresas causadoras de grandes malefícios sociais decorrentes de fraudes e de condutas contra a ordem econômica, as ações da Polícia Federal desencadeadas na Operação Lava-Jato acabaram resgatando reflexões sobre o certo e o errado, sobre o lícito e o ilícito, sobre o agir conforme a lei e não infringir os preceitos legais, de tal modo a colocar a ética - tida aqui como 
elemento propulsor do compliance - como padrão de conduta indispensável para tomada de decisões.

Diante desse quadro, considerando tamanha importância de se implantarem códigos de ética nas organizações e de se criarem e operacionalizar compliance como meio de cumprimento das normas e leis, a pergunta que faz é a seguinte: o homem nasce puro e a sociedade o corrompe ou ele estaria predisposto a obter ganhos mesmo ilicitamente?

Do mesmo modo, as vantagens econômicas apresentadas a cada ser humano detêm certa função que externa poder são passíveis de objeção ou faz parte de um ritual praticado na sociedade, produto de um sistema em que a ganância é o elemento formador das decisões?

Por se tratar de um artigo exploratório sobre as condutas humanas para entender as ações corruptivas sociais, não há como investigar as razões antropológicas e os perfis psicológicos a fundo, mesmo porque tais indagações esbarram em diversas linhas de pensamento, que poderiam trazer complexidade no auxílio ao leitor ou ao próprio gestor de negócios.

Busca-se, no entanto, encontrar fundamentos epistemológicos, a partir de premissas e proposições feitas por filósofos e economistas, com respaldo em tendências e ciclos de condutas humanas, que revelam ganâncias e temperanças e, assim, propiciar uma pesquisa pelos canais empíricos que as próprias organizações produziram ao longo da história. Assim e dessa forma se coloca à baila a contribuição social deste singelo estudo.

\section{Desenvolvimento}

\subsection{Metodologia}

Este estudo teve como premissa uma análise sobre algumas das publicações de autores renomados da literatura a respeito das publicações sobre o compliance e sua regulação junto às ações empresariais.

Assim, o estudo se caracteriza como uma pesquisa bibliográfica, pesquisa teórica como análise do estado da arte, de natureza qualitativa, tendo como pano de fundo as publicações realizadas e uma análise dessas por parte dos autores.

\subsection{O Homem como ser intelectual}

Conceituar o ser humano é uma missão muito complexa.
A dificuldade se torna ainda maior quando os estudos diferenciam concepções sobre o vernáculo homem e a palavra composta ser humano. A dualidade entre o homem como pessoa identificável, singular e física e o ser que envolve sua psique, seus pensamentos e seus desejos são reiteradamente estudados e suas definições são estruturadas, a partir de sua interação com os demais seres vivos ou inanimados, que existem no mundo (MORIN, 1973).

Os significados desses vernáculos (homem e ser humano) são por demais complexos e intrigantes. Por mais simples que suas identificações possam se apresentar à sociedade, essas transmitem ao leitor mais atento um debate de pretensões "ontológicas" (ser enquanto ser) ou "fenomenológicas" (experimentos feitos para designar não uma coisa, mas um processo, uma ação que se desenrola no tempo, em que o homem está envolvido). ${ }^{1}$

O homem é um ser gregário por essência e sua relação com os demais seres e com a natureza está fundada em um conjunto de linguagens cotidianas produzidas, reproduzidas e modificadas ao longo da história.

As ideias são reflexões singulares do ser humano. De um modo geral, as ideias surgem em um mundo submerso da mente, despertadas a partir da observação ou provocação de algo diferente em seu mundo exterior. Nessas circunstâncias empíricas, o homem depura a utilidade da informação, alimenta sua mente do problema - imaginação - e, após um determinado tempo de maturação, expressa uma resposta para a questão sobre a qual se deparou.

É nesse universo nebuloso de pensamentos e de ideias, que brotam situações provocadoras - causas - nas quais o homem se destaca dos demais seres, suscitando questionamentos ${ }^{2}$ (HAAR, 1990) e revelando inquietudes alinhadas até mesmo sobre quais são as razões de sua existência e quais são os objetivos desse nesse mundo ${ }^{3}$ (HUME, 2009).

A ação do homem decorre de uma provocação de seu intelecto captada em um ambiente, em que ele busca solucionar um conflito. O conflito é gerado pela reflexão de sentimentos provados por fatos exteriores ou por dúvidas da interação do homem com a natureza e com os seus pares.

Heidegger aponta que a inquietude do homem advém de sua observação sobre o meio. O ser humano necessita descobrir-se para buscar a verdade, que ronda seu meio. Essa provocação de buscar algo a mais, o diferencia dos demais

1 Muitos filósofos se debruçaram para desvendar um conceito próximo do "ser", desde os pensadores pré-socráticos até os modernos. A definição do "ser humano" sobre ponto de vista "axiológico" (teoria dos valores em geral, especialmente, os valores morais) ou pelo "empirismo" (teoria do conhecimento, segundo o qual todo conhecimento humano deriva, direta ou indiretamente, da experiência sensível externa ou interna), é um debate filósofo que se renova diariamente, em tentativas de se entender a complexidade das ações humanas e dos mistérios de sua mente. Filósofos, antropólogos, sociológicos, psicólogos renovam a identificação do "ser humano" a cada crise social, ou a cada fato que revela intolerâncias ou excessos do indivíduo em suas comunidades.

2 Heidegger entende que o "questionamento é a devoção do pensamento". O termo "devoção" indica o "coração mais íntimo, a fonte essencial do pensamento: durante o tempo em que se mantém salvo o questionamento, o pensamento permanece vivo e aguarda um futuro.

3 David Hume observa que o pensamento e a reflexão estão relacionados com uma causa. "Para começar de maneira ordenada, devemos considerar a ideia de causação, e examinar qual sua origem”. E, portanto, é "impossível raciocinar de maneira correta sem compreender perfeitamente a ideia sobre a qual raciocinamos; e é impossível compreender perfeitamente uma ideia sem referi-la a sua origem, e examinar aquela impressão primeira da qual ela surge. $\mathrm{O}$ exame da impressão confere clareza à ideia; e o exame da ideia confere uma clareza semelhante a todos os nossos raciocínios. 
seres. O "elemento do homem, o seu solo abissal, é o ser, estranho meio que não contém, mas que o transporta e o exporta". ${ }^{4}$ (HAAR, 1990).

$\mathrm{O}$ que distingue, significativamente, o homem com os demais seres é o "pensar". O raciocínio transporta o homem a outros universos, diferentes e longínquos daqueles em que vive. O "pensar" humano eleva a capacidade intelectual do homem sobre os outros seres, porque o ser humano não somente "percebe as coisas exteriores", mas também questiona seu "próprio ser interior". Toma, por consequência, a "consciência de sua realidade subjetiva, de seu ser próprio como tal e distinto do ser das demais coisas".

Esses diferenciais tornam o homem um ser político ${ }^{5}$, que na visão aristotélica decorre do fato de os homens viverem em um mesmo local, participando "em comum" das coisas. Esses mesmos homens poderiam escolher também não participar das coisas da vida em comum. Porém, de "nada participar é impossível, sem dúvida; porque a sociedade política é uma espécie de comunidade" (ARISTÓTELES, 2011).

A interação é substantivo que designa o ato humano direcionado ao fim comum entre pessoas $[$ inter $=$ entre + agere $($ latim $)=$ realizar, fazer]. Essa ação entre pessoas e coisas, ou entre objetos e seres humanos, conduz a uma interatividade indispensável de pessoas que vivem em comunidade e carecem da troca de informações ou conhecimentos para reflexão individual.

O próprio questionamento do ser humano e a necessidade de interagir com outros são fatos decorrentes do "pensar" humano. O intelecto de cada homem é revelado à medida que questionamentos são feitos e as dúvidas são solucionadas por outros homens integrados em um mesmo meio.

Para Arendt (2013), a política, então, é produto da ação do homem porque ele, ao viver em comunidade, compartilha ideias, pensamentos com outros seres. Essas outras pessoas, que convivem em comunidade, se tornam uma "multidão de pessoas", como resultado da multiplicação natural das relações humanas.

Por ser político, a comunhão dos seres humanos revela a multiplicidade de seres pensantes. Para Arendt (2013), a pluralidade é a condição humana, porque são todos iguais, isto é, humanos, de um modo tal que ninguém jamais é igual a qualquer outro que viveu, vive ou viverá.

Para Derisi (1963), em decorrência da ação humana e porque o homem vive em sociedade, que ele é capaz de criar “cultura ou humanismo". E, portanto, é "capaz de fazer crescer consciente e livremente o ser ou bem das coisas exteriores e de si mesmo". Por seu espírito cognitivo, o homem pode "aprender e realizar o bem ou o valor."

\subsubsection{A Ação como Função Transformadora do Homem}

Aristóteles (2009) analisou o homem a partir das consequências que a ação humana era difundida pelo meio social da polis. ${ }^{6} \mathrm{~A}$ ação, como resultado de uma força física ou moral, como ato, feito, obra ou resultado de executar alguma coisa é a inerente do ser humano, que vive em sociedade. A ação humana, para o bem ou para o mal, conduz à investigação, a partir de seus "múltiplos empreendimentos", de seus vários alcances, assim como suas "finalidades".

O meio ambiente reproduz circunstâncias que também devem ser balizadas para julgamento de um ato humano. Se o homem é um ser provido de ação, é porque ele conquistou a liberdade para produção de seus atos no meio social em que vive.

Bobbio (2000) considera a ação como resultado da liberdade. Liberdade significa a faculdade de cumprir ou não certas ações, sem o impedimento dos outros que comigo convivem - nota-se, nesse trecho, a presença de outros que vivem em comunhão com o eu - ou da sociedade, como complexo orgânico ou, mais simplesmente, do poder estatal.

O "ser livre" é gozar de uma esfera de ação, mais ou menos ampla, não controlada pelos órgãos do poder estatal. De outro aspecto, dentro de uma doutrina democrática, é também poder participar e criar leis, que possam servir de controle da paz social (BOBBIO, 2000).

A ação humana, pois, deriva da própria observação reflexão - feita pelo ser humano em relação ao meio em que vive e explora.

Arendt (2009) observa que a "ação, única atividade que ocorre diretamente, sem a mediação das coisas ou da matéria, corresponde à condição humana da pluralidade", fazendo com que essa pluralidade justifique a vida política do homem.

Não existe somente um homem, mas a pluralidade de homens. E por existir essa pluralidade, o ser humano comunga com os demais seres e com a natureza, agindo e interagindo com o meio para sua subsistência.

Para Arendt (2009), por viver em sociedade, e assim dizer, na visão aristotélica, que o homem é um ser político, a política se baseia no fato da pluralidade humana. Do mesmo modo, os homens são um produto humano, terreno, um produto da natureza humana.

4 Michel Haar explica que para o "sofista Protágoras, o homem é, por certo, a medida de todas as coisas mas ele obedece à lei de uma sofhia, que lhe prescreve as estritas fronteiras do seu reino e do seu saber. O homem cartesiano, kantiano, delimita e assume a finitude de uma vontade de conhecimento, todavia infinita no seu princípio. O homem das ciências humanas, cedendo à vontade da vontade, explora o seu próprio chão, reparte-se em setores objetiváveis e mensuráveis, projeta-se o grande filme inacabado do seu ativismo ilimitado.

5 A palavra política tem origem da palavra latina politicus, do grego politikós e diz respeito a tudo aquilo que relaciona os cidadãos ao governo da cidade, e assim, aos negócios públicos. A palavra polis, no séc VI a.C, que é base construtiva da palavra política, constituía-se como uma unidade política e territorial, sobretudo, através do vínculo que seus cidadãos mantinham com ela por lealdade, identidade cultural e origem.

6 Polis tem o significado de cidade, ou seja, lugar formado por um pequeno território e por uma população. Era o nome dado à cidade-estado da civilização grega, na antiguidade. 
A ação humana proporciona efeitos diretos e indiretos no meio em que ele vive. Esses efeitos possibilitam ao homem refletir sobre a utilidade, a necessidade e até mesmo o prazer de realizar determinada ação. Dependendo da ação produzida e o resultado obtido, pode ou não subsistir um condicionamento do homem para realizar novas ações ou abandoná-las.

Para Hume (2009), o homem é movido por uma "causa" e, essa "causa" gera efeitos sobre o meio social. Existe uma relação entre "causa" e "efeito", que conduzem o homem à interação mútua. Desde a reflexão sobre algo até a exteriorização de seu pensamento sobre determinado fato, o homem "produz" algo por força de uma causa antecedente. ${ }^{1}$

A produção, como derivativo de ação, tem por objetivo proporcionar algo real na vida humana, pois "tudo que é produzido sem causa é produzido por nada". Enfatizando esse pensamento, ação sem causa antecedente geraria produção despropositada, ou seja, para o nada, para o vazio. Logo, deve-se perceber que a existência de todo objeto possui uma causa real.

Von Mises (2010) utiliza a expressão “acting man", para demonstrar que a ação humana também envolve "agente homem" ou outras formas como "homem em ação" ou "homem que age". Para justificar a tese de que o homem age com um propósito, o autor afirma que a ação humana é comportamento propositado. A “ação é a vontade posta em funcionamento, transformada em força motriz; é procurar alcançar fins e objetivos; é a significativa resposta do ego aos estímulos e às condições do seu meio ambiente".

Desde o nascimento, através de movimentos indicadores de sentimentos e de expressões de felicidade ou de dor, a criança exterioriza aos seus pares seus desejos ou insatisfações. Essa mesma criança, até momentos finais de sua vida, também conjuga expressões ou linguagens, que manifestam sua vontade. Do nascimento à morte, durante o convívio com seus pares e com a sociedade, o homem se expressa por meio de ações propositadas.

Se para David Hume a causalidade antecede a exteriorização da ação, ou vale dizer, que para toda a ação é indispensável uma causa para que essa se desenvolva, para Von Mises o entendimento é que o ser humano age quando está insatisfeito, ou melhor, que pode não agir quando há o contentamento ou a satisfação do homem em relação ao meio. A ação depende de um comportamento consciente e propositado para algo, indiferente de reflexos ou de respostas involuntárias do corpo a estímulos.

Von Mises (2010) ressalta que o agente homem está ansioso para substituir uma situação menos satisfatória, por outra mais satisfatória. A mente do homem imagina situações que lhe_são mais propícias, e sua ação procura realizar esta 1 situação, ou seja, um homem satisfeito com sua situação não teria incentivo para mudar as coisas. E, ainda, não teria aspirações, desejos.

Parte-se, então, da premissa histórica - aqui exemplificada desde a descoberta do fogo até a invenção do microcomputador - que o homem, utilizando-se de seu intelecto, buscou sempre agir para aprimorar suas condições de vida ou de suprimir seu desconforto com aquilo que o cerca.

Para Galimberti (2006), as criações e ações são "determinadas pelos julgamentos de valor dos agentes individuais, isto é, pelos fins que pretendem obter e pelos meios que utilizam para atingir esses fins". As circunstâncias ou a época em que devem ocorrer as mudanças dependerão do conjunto de ações e de decisões tomadas pela sociedade. E tudo dependerá dos propósitos dos agentes dominantes da sociedade, pois a escolha dos meios é o resultado do conjunto de conhecimentos tecnológicos dos agentes individuais.

\subsubsection{O Homem Empreendedor: o surgimento das sociedades empresariais}

As sociedades empresariais são criações do homem. Uma organização empresarial é fruto de uma associação, que busca produzir com eficiência e correta alocação de recursos através de uma mão de obra especializada.

Não haveria organizações se não tivesse a livre manifestação de vontade do homem de criar um modelo de sociedade em que, através de uma divisão preestabelecida, alguns administram recursos obtidos pela junção de investimentos, enquanto outros executam as tarefas previamente relacionadas para atingir os objetivos traçados.

Daí se acreditar que a sociedade empresarial é criada para atender uma determinada missão, ou seja, um objetivo social, cuja finalidade de seus sócios acionistas é a de obter lucros compensatórios pelo investimento.

A realização da missão da empresa se torna relevante no momento em que essa emprega pessoas, aloca seus recursos, cria uma filosofia de trabalho, levando benefícios a toda sociedade.

Os trabalhadores representam o cerne de uma organização: eles podem levar a empresa ao sucesso ou fazê-la estagnar no mercado. Tudo dependerá da forma de gestão das pessoas e da alocação de recursos humanos.

De Masi (2003) adverte que o homem possibilitou o fortalecimento de cada atividade, cognitiva e operacional, a um nível desconhecido em todas as épocas anteriores da história, dentro e fora dos locais de trabalho. Na prática cotidiana, partindo das "grandes descobertas de Taylor e Ford", trabalhadores "revolucionaram o modo com que os seres humanos organizam seus próprios recursos e aumentam seu rendimento"(DE MASI, 2003).

\footnotetext{
7 No entendimento de David Hume, não que toda produção de algo pressupõe causa anterior. Um objeto pode ser contíguo e anterior a outro, sem ser considerado sua causa. No entanto, Hume entende que existem "relações" entre uma "produção" e uma "causa", ou seja, para que exista algo, há a causalidade geradora para justificar essa produção. Para Hume: Trata-se de uma máxima geral da filosofia que tudo que começa a existir deve ter uma causa para sua existência.
} 
Drucker (2008) adverte que a empresa não tem nada a ganhar, mas sim a perder, se a capacidade de desempenho dos trabalhadores de uma organização no seu propósito estiver reduzida ou enfraquecida. E isso importa no desempenho em realizar uma ação social. "O desempenho de sua função é primeira responsabilidade social da instituição. Se o seu desempenho não for responsável, não mais o poderá ser."

O impasse de interesses entre o capital e o trabalho é tema relevante e foi levantado por Marx durante sua investigação no final do século XIX. Até hoje, o problema da distribuição de riquezas e o acúmulo de ganhos, por parte da minoria, é tema de grandes discussões, pois não há como ceder aos encantos dos versos da necessidade de ser repartir os lucros, sem antes se atentar para os reais sacrifícios feitos pelos investidores, que colocaram tudo em risco para obter uma vantagem econômica no futuro.

A questão que pesa é se os gestores estão ou não agindo com responsabilidade social e se realmente haveria necessidade de se criar um Código de Ética para traduzir o certo do errado ou, ainda, aquilo que se pode deduzir por bem ou por mal.

Decerto, os gestores não podem permanecer prisioneiros da sua própria ignorância em relação à necessidade objetiva de lucro sem se preocupar com a responsabilidade social. Se somente pensarem e agirem dessa forma, não serão capazes de tomar decisões racionais relativamente às responsabilidades sociais da empresa e nem de respaldar suas decisões dentro e fora de seus escritórios.

Para melhor explanação sobre o tema, é interessante entender que as normas servem para regulamentar as condutas humanas. O objetivo da norma é traduzir ou esclarecer para os homens o que pode ser feito e o que não pode ser feito. $\mathrm{E}$ para as organizações se pode também implantar tais regras de conduta para evitar erros ou causar prejuízos?

Ainda, para Drucker (2008), uma instituição, especialmente uma empresa, precisa adquirir as competências necessárias para assumir a responsabilidade pelos seus impactos Toda vez que uma empresa "desprezou as limitações do desempenho econômico e assumiu responsabilidades sociais que não conseguia comportar economicamente, depressa se viu em apuros."

A organização moderna existe para prestar um serviço à sociedade. Os impactos e problemas sociais decorrentes de sua atividade devem ser reordenados de tal modo a evitar ocorrências danosas para o meio-ambiente e para todos aqueles que, direta ou indiretamente, usufruem de seus produtos e serviços.

\subsection{3 Ética e Compliance como modelo de regulação das ações empresariais}

A ética traduz um significado de dever-ser, de agir conforme o bom senso, de fazer aquilo que é bom para todos. Para Comparato (2006), a ética possui como primeiro princípio "não fazer o mal a ninguém" e como segundo princípio, "fazer o bem a todos, sejam eles amigos, desconhecidos ou inimigos".

O homem, portanto, ainda que inconscientemente, sabe que fazer o bem ao outro traz um resultado positivo e um conforto pessoal inexprimível, sobretudo, porque quando ele experimenta o contrário - fazer o mal - seus sentimentos ficam abalados, preocupantes e incomodados.

A boa ação, portanto, depende de uma conduta reprodutora de pensamentos dirigidos a um fim que não seja fazer o mal. Fazer o mal, ainda que não objetivamente, resulta na responsabilidade dos agentes econômicos ou dos detentores do poder para cada fato, que atinja toda a sociedade.

Para Frederick (2008), ao invés de limitar a análise e aos valores de dada sociedade ou período, as linhas gerais normativas para os negócios devem "refletir as conquistas do conhecimento e da experiência do homem: os negócios devem acontecer e ser entendidos dentro de um todo. O universo não gira em torno da empresa, nem essa merece status central ou especial."

No espaço da reflexão ética, cabe ao administrador se preocupar com a promoção de valores e comportamentos morais, que respeitem os padrões universais de direitos humanos e de cidadania e participação da sociedade, respeitando o meio ambiente e contribuindo para a sustentabilidade em todo o mundo.

O compliance surge como procedimento de regulação de condutas. Compliance deriva do verbo inglês "to comply", significa cumprir regras, normas, diretrizes ou, simplesmente, responder a um comando.

Nas relações organizacionais, os "executivos devem conter seus instintos" e ter em mente que o "excesso de ambição e a visão do lucro imediatista prejudicam a empresa em longo prazo". Do mesmo modo, os investidores "precisam despir-se de atributos negativos, instintos nocivos e paixão exagerada pelo material" (GARCIA CAVERO, 2014).

Cabe ao administrador agir dentro de um comportamento ético voltado à manutenção de valores, que exprimam mais o sentimento de humanidade e solidarismo, buscando a otimização de seus recursos para obtenção do lucro desejado pelos empresários. Deve, pois, o administrador, harmonizar a sustentabilidade da empresa no mercado com a valorização do trabalho humano, investindo em novas tecnologias para sobreviver em meio à competição e nunca se esquecer, ainda, que o Direito tem como pressuposto garantir a todos uma existência digna, devendo essa regra servir de sustentação maior para reger a ordem econômica.

Para Garcia Cavero (2014), a implantação do compliance na empresa é de extrema importância. Isso porque o compliance representa a difusão de normas balizadoras de decisão no mundo de negócios. São diretrizes e medidas destinadas a assegurar a observância de leis, "estandartes e diretivas empresariais". Existe, portanto, "certa ambivalência de sua acepção: em termos amplos, refere-se à observância de 
parâmetros não só legais, mas também de caráter ético e de política empresarial", e de outro lado, "em sentido estrito", faz referência a uma normativa legal, que deve ser cumprida integralmente.

Para Santos, Hoyos Guevara e Amorim (2013), o compliance possui várias causas e são influenciadas pelas circunstâncias. Na raiz da conduta corrupta está a percepção moral, a compreensão do indivíduo sobre o significado de sua atitude ante a moral e as regras organizacionais. Discutir compliance exige compreender a natureza e a dinâmica da corrupção nas organizações.

A lei anticorrupção, uma das últimas normas que clamam a necessidade de criação de Códigos de Conduta, determina que as pessoas jurídicas sejam responsabilizadas, objetivamente, nos âmbitos administrativo e civil, pelos atos lesivos, previstos nesta Lei, praticados em seu interesse ou benefício, exclusivo ou não. A responsabilização da pessoa jurídica não exclui a responsabilidade individual de seus dirigentes ou administradores ou de qualquer pessoa natural, autora, coautora ou partícipe do ato ilícito.

Além disso, a citada lei prevê como atos lesivos à administração pública, nacional ou estrangeira, que violem os princípios da administração pública ou contra os compromissos internacionais assumidos pelo Brasil, definidos como: prometer, oferecer ou dar, direta ou indiretamente, vantagem indevida a agente público, ou a terceira pessoa a esse relacionada; financiar, custear, patrocinar ou de qualquer modo subvencionar a prática de atos ilícitos; utilizar-se de interposta pessoa física ou jurídica para ocultar ou dissimular seus reais interesses ou a identidade dos beneficiários dos atos praticados; frustrar ou fraudar, mediante ajuste, combinação ou qualquer outro expediente, o caráter competitivo de procedimento licitatório público; fraudar licitação pública ou contrato dessa decorrente.

Esse conjunto de medidas legislativas, entre outras já existentes, revela a necessidade emergencial de as organizações implantarem o compliance, que representa a execução e o cumprimento de disciplinas da organização, a fim de fiscalizar a tomada de decisões e a integridade da empresa, evitando condutas fraudulentas, que visem obter vantagens ilícitas ou comprometa os investimentos dos sócios e demais grupos de interesse.

Para Drucker (2008), os impactos de novas leis, que reforçam a necessidade de uma conduta ética na sociedade e na economia, traçam novos modelos de ações organizacionais com responsabilidade social, sobretudo, em ações que não contenham, em si mesmo, "a finalidade e a missão da instituição", pois as condutas ilícitas devem ser restringidas ao mínimo e devem, preferencialmente, "ser eliminados por completo".

A empresa tem responsabilidade social que deve ser considerada na própria atividade-fim da organização. A lógica não pode ser somente o lucro. O lucro é necessário para a empresa sobreviver e competir no mercado em que atua, mas a ética e a responsabilidade social da empresa é que a torna uma ação instrumental de implementar dos objetivos principais da Constituição Federal, entre esses, o de construir uma sociedade livre, justa e solidária.

Dentro e fora do ambiente do trabalho, o empresário deve conduzir seus negócios com eticidade e boa-fé, levando em conta, sobretudo, a função socioeconômica da empresa. Caso não tome uma postura positiva, buscando o bem da organização empresarial, o sistema produtivo perderá qualidade e a proliferação do descontentamento dos colaboradores acabará criando mais marginalização e exclusão social.

Nas relações de trabalho, os colaboradores devem atentar para o fato de que eles passam o maior tempo de suas vidas no ambiente laboral. Durante as jornadas de trabalho, os colaboradores se reúnem para tomar decisões, organizam atividades de acordo com as habilidades de cada trabalhador, enfim desempenham todas as funções necessárias para que a empresa atinja seus objetivos.

Para Sennett (2009), a moderna ética do trabalho concentra-se no trabalho em equipe. Celebra a sensibilidade aos outros; exige 'aptidões delicadas', como ser um bom ouvinte e cooperativo. $\mathrm{O}$ trabalho em equipe representa a ética de trabalho de uma economia política flexível.

Para Sennett (2009), apesar de todo o "arquejar psicológico da administração moderna sobre o trabalho de equipe", o autor entende que é o "etos do trabalho que permanece na superfície da experiência. $\mathrm{O}$ trabalho de equipe é a prática de grupo da superficialidade degradante".

A ética no trabalho, em linhas gerais, não pode ser aprimorada a partir de uma década para outra, de um momento histórico para um evento atual, de uma era clássica para uma era moderna. Essa sempre existiu e, de alguma forma, foi buscada, reproduzida e ajustada nos ambientes do trabalho.

O compliance surge para regulamentar o que ficou condenado em práticas negociais antigas para impor uma nova condição para realização de negócios sustentáveis.

Dupas (2001) acentua que a "divisão social do trabalho se subverte pela contínua evolução dos sistemas técnicos, motivo pelo embate estratégico da concorrência" A técnica em expansão, embora "abra novos domínios ao poder criador e à atividade dos homens, está a serviço do capital e de sua acumulação".

O trabalhador inserido na empresa se submete a uma diversidade de funções e, embora esteja rodeado de novas tecnologias, acaba subvertendo sua capacidade de compreensão do que é verdadeiramente útil e qual a razão de se produzir algo senão em virtude do sacrifício de seu tempo em troca de remuneração.

A ética, na sociedade da informação, está voltada não somente a uma conduta pautada na boa-fé e no desejo de seu propagar um bem comum a todos os participantes da empresa, mas também a uma dimensão maior, que transcende o ambiente de trabalho.

O empregado deve se inteirar dos acontecimentos que 
ocorrem dentro e fora da empresa, pois detém meios de captar a informação e deverá transformá-la em conhecimento, a fim de exigir mudanças organizacionais, que possam propagar benesses a toda população e aos grupos de interesses.

Dupas (2001) comenta se as relações de emprego ainda se edificarem no individualismo ou em um estado de "vazio ético", no qual as referências são as "delícias do narcisismo", e no uso imoderado da informação como forma de poder interno com relação aos seus pares, os homens acabarão regredindo em seu tempo. Critérios de um "vago humanismo, colorido" por individualismo "ligeiramente otimista e materialista já não bastam para lidar" com os poderes organizacionais.

Dentro das empresas, o compliance alimenta um organizado sistema comportamental, disciplinado por normas, que devem ser cumpridas por todos os agentes envolvidos, voltada para o fortalecimento das relações entre os detentores do poder de decisão e seus subordinados, com o propósito principal de viabilizar a organização atingir seus objetivos de forma sustentável, com redução de riscos internos, agregando interesse de todos os grupos envolvidos, evitando danos à reputação empresarial.

\section{Conclusão}

O desafio do administrador, a partir da edição de novas leis, que buscam afastar condutas danosas aos setores públicos e privados, deve se pautar na manutenção e preservação da empresa como ser vivo, atuante proativamente no mercado econômico, vinculando-se a um Código de Conduta elaborado a partir do que ficou assentado sobre o que é ser certo ou errado, justo ou injusto, coerente ou abusivo, a fim de que não tome decisões abusivas no comando da organização.

$\mathrm{Na}$ busca do bem comum, o administrador deve cumprir os objetivos da empresa e, ao mesmo tempo, agir com responsabilidade social. Deve o gestor apresentar e executar um projeto de gestão de negócios, de forma a equacionar a necessidade de se obter os lucros desejáveis aos sócios e investidores da empresa, comprometendo-se a cumprir os desígnios traçados pela diretoria, desde que respeite os princípios, que norteiam a ordem econômica.

No exercício de sua função, o administrador tem que sustentar suas condutas na valorização do trabalho humano, respeitando a função social da propriedade, a livre concorrência, a defesa do consumidor e a defesa do meio ambiente, observando, inclusive, o impacto ambiental dos produtos e serviços colocados em circulação na sociedade.

O compliance representa uma autorregulação da sociedade empresarial, com objetivos específicos para todos os gestores e trabalhadores de executar suas funções dentro de padrões concebidos como corretos e não lesivos à sociedade.

As empresas, que não cumprirem as normas previstas em Códigos de Conduta, assim como seus gestores e trabalhadores, apuradas e identificadas a responsabilidade individual e pessoal de cada agente, responderão objetivamente por danos causados ao meio ambiente, à ordem econômica, ao sistema financeiro e ao erário público.

Os novos padrões de comportamento instituem, portanto, a ética como pilar filosófico e jurídico para adoção de padrões rigorosos na administração das empresas, seja pela necessidade das próprias organizações de adaptar a um controle mais apurado das condutas de seus agentes, com a finalidade de manter sua boa reputação perante clientes, fornecedores e consumidores, seja em decorrência dos efeitos de legislações editadas pelo Poder Público para obrigar, que todas as organizações atuem de acordo com padrões regulatórios fixados pelos agentes públicos e por toda sociedade.

\section{Referências}

ANTONIK, L.R. Compliance, ética, responsabilidade social e empresarial: uma visão prática. Rio de Janeiro: Alta Books, 2016.

ARENDT, H. A condição humana. Rio de Janeiro: Forense Universitária, 2013.

ARENDT, H. A promessa da política. Rio de Janeiro: DIFEL, 2009.

ARISTÓTELES. A política. Rio de Janeiro: Nova Fronteira, 2011.

ARISTÓTELES. Ética a Nicômaco. Bauru: Ediro, 2009.

BOBBIO, N. Teoria geral da politica: a filosofia política e as lições dos clássicos. Rio de Janeiro: Elsevier, 2000.

COMPARATO, F.K. Ética: Direito, moral e religião no mundo moderno. São Paulo: Companhia das Letras. 2006.

DE MASI, D. O futuro do trabalho: fadiga e ócio na sociedade pós-industrial. Rio de Janeiro: José Olympio, 2003.

DERISI, O.N. Valores básicos para a construção de uma sociedade realmente humana. São Paulo: Mundo Cultural, 1963.

DUPAS, G. Ética e poder na sociedade da informação. De como a autonomia das novas tecnologias obriga a rever o mito do progresso. São Paulo: Editora UNESP, 2001.

DRUCKER, P.F. O essencial de Drucker. Lisboa: Actual, 2008.

FREDERICK, W.C. Moving to CSR4: what to Pack for the trip. Bus. Soc., v.37, n.1, p.40-59, 1998.

GALIMBERTI, U. Psiche e techne: o homem na idade da técnica. São Paulo: Paulus, 2006.

GARCIA CAVERO. P. Criminal compliance. Lima: Palestra, 2014.

HAAR, M. Heidegger e a essência do homem. Lisboa: Instituto Piaget. 1990.

HUME, D. Tratado da natureza humana: uma tentativa de introduzir o método experimental de raciocínio nos assuntos morais. São Paulo: UNESP, 2009.

JAPIASSÚ, H.; MARCONDES, D. Dicionário básico de filosofia. Rio de Janeiro: Jorge Zahar, 2008.

MARTINS, M.M.M. A empresa e o valor do trabalho humano. São Paulo: Almedina, 2015.

MORIN, E. Le paradigme perdu: la nature humaine. Paris: Edition du Seuil, 1973.

SANTOS, R.A.; HOYOS GUEVARA, A.J.; AMORIM, M.C.S. Corrupção nas organizações privadas: análise da percepção moral segundo gênero, idade e grau de instrução. Rev. ADM., v.48, n.1, p.53-66, 2013 
MARTINS, M.A.M.M. et al.

SENNETT, R. A corrosão do caráter: consequências pessoais do trabalho no novo capitalismo. Rio de Janeiro: Record, 2009.
VON MISES, L. Ação humana. São Paulo: Instituto Ludwig von Mises Brasil, 2010. 